\title{
Predicting Outcome following Colorectal Cancer Surgery using Colorectal Biochemical \& Haematological Outcome Model (Colorectal BHOM)
}

N Farooq ${ }^{1}$ MRCS, A J Patterson ${ }^{2}$ PhD, S R Walsh ${ }^{3}$ FRCS, D R Prytherch ${ }^{4}$, T A Justin ${ }^{1}$ FRCS, T Y Tang ${ }^{2,3}$ MD MRCS

${ }^{1}$ Department of General Surgery, West Suffolk Hospital, Bury St Edmunds, Suffolk, UK

${ }^{2}$ University Department of Radiology, Cambridge University Hospitals NHS Foundation Trust, Cambridge, UK

${ }^{3}$ Department of General Surgery, Norfolk \& Norwich University Hospital NHS Foundation Trust, Norfolk, UK ${ }^{4}$ TEAMS Centre, Queen Alexandra Hospital, Portsmouth, UK

\section{Corresponding Author:}

Mr. T Y Tang MRCS

Specialist Registrar

Box 218; Level 5

Cambridge University Hospitals NHS Foundation Trust

Hills Road

Cambridge CB2 OQQ

United Kingdom

Tel: $+44(0) 1223217246$

Fax: $+44(0) 1223216015$

E-mail: tt279@cam.ac.uk

Competing Interests: none declared

Funding: None

Key Words: surgical audit; complications; scoring; $\mathrm{BHOM}$; colorectal cancer 
Manuscript Category: original article

Word count: Text 2526, Abstract 240 words 


\section{Abstract}

Background: There is a niche for developing an ideal pre-operative scoring system for predicting mortality in patients undergoing colorectal surgery. Biochemistry and Haematology Outcome Models (BHOM) adopt the approach of using a minimum dataset to model outcome following colorectal cancer surgery, a concept previously shown to be feasible after index arterial operations.

Methods: Predictive binary logistic regression models (a mortality and morbidity model) were developed on 704 patients who underwent colorectal cancer surgery over a six-year period in a UK district general hospital. The outcome variables measured were 30 day post-operative mortality, and morbidity (defined as major/minor leak, abscess, bleeding or obstruction). Hosmer-Lemeshow goodness of fit statistics and frequency tables compared the predicted versus the reported number of deaths. Discrimination was quantified using the c-index.

Results: The dataset consisted of 573 elective cases and 131 non-elective interventional cases. The overall mean predicted risk of death was $7.79 \%$ (50 cases). The actual number of reported deaths was also $50\left(x^{2}=1.331\right.$, d.f. $=4, p$ value $=0.856$; no evidence of lack of fit). For the mortality model, the predictive $c-$ index was $=0.810$. The morbidity model had less discriminative power, however, there was no evidence of lack of fit $\left(x^{2}=4.198\right.$, d.f. $=4, p$-value $=0.380, c$-index $=$ 0.697).

Conclusions: The CR BHOM mortality model suggests good discrimination (c-index $>0.8$ ) and uses only a minimal number of variables. However, the model needs to be tested on independent datasets from different geographical locations. 


\section{Introduction}

In recent years, several prognostic scoring systems have been developed and validated in different geographical settings for the assessment of mortality in colorectal cancer surgery. They can be used as performance indicators to allow objective comparisons between surgeons and surgical units because they adjust for patient-related risk factors and operative severity (case mix).

The Physiology and Operative Severity Score for enUmeration of Mortality and morbidity (POSSUM) and Portsmouth POSSUM (P-POSSUM) were originally developed to predict the outcomes of general surgical patients ${ }^{1,2}$. A major drawback of the POSSUM methodology is that it requires the collection of 12 pre-operative physiological variables and 6 operative variables, which is time consuming and precludes the opportunity to obtain a purely pre-operative risk assessment. The Biochemistry and Haematology Outcome Model (BHOM) adopts a different approach; it uses a minimal data set to model outcome and has previously been shown to be effective with index arterial operations (vascular or VBHOM) ${ }^{3-6}$. VBHOM is based on a minimal dataset derived from National Vascular Database haematology and biochemistry data items, which can all be obtained pre-operatively. They are easy to collect from hospital pathology and patient administration computer systems and they are collected routinely during normal clinical care, hence data collection is not an additional burden.

The aim of this study was to develop a new BHOM equation (Colorectal- or CR$\mathrm{BHOM}$ ) using only a minimum number of variables to predict post-operative outcomes for patients undergoing colorectal cancer resection. 


\section{Methods \& Patients}

The modelling was performed using data from a single, medium-sized (600 bed) district general hospital in the United Kingdom. The unit manages about 150 new patients with colorectal cancer each year. A database is maintained by a team of colorectal nurse practitioners and a dedicated data clerk. The database is based upon the Association of Coloproctology's (ACP) minimum dataset as specified for version 2.0 of the ACPGBI colorectal cancer database (www.nbocap.org.uk/datasets). Every patient is entered prospectively and the record is regularly updated during follow-up. Data are submitted annually to the Association of Coloproctology of Great Britain \& Ireland for comparative audit. Consecutive patients undergoing elective or emergency colorectal resection entered into the database from its inception in mid 2001 until September 2007 were used as the study population. Post-operative death was recorded. Post-operative morbidity was recorded as the occurrence of any of the pre-defined complications (major or minor leak, abscess, bleeding or obstruction-table 1).

The following data items were extracted from the database: discharge status of patient, admission date and discharge date, age at admission, mode of admission, gender, haemoglobin, white cell count, urea, creatinine, albumin, sodium and potassium levels. These blood tests were taken on admission or immediately before surgery. The cases were then ordered by dead/alive status at 30 days and age at admission. Binary logistic regression was performed on this data to form a model of adverse clinical outcome (30-day mortality and complication).

It is important to have an adequate number of events (deaths or complications) in each set to model outcome using logistic regression. As a rule, at least ten outcome 
events per potential predictor variable are required to minimise the risk of a Type I error $^{7}$.

\section{Statistical Analysis}

Within the logistic regression model mode-of-admission was modelled as follows: $1=$ elective and $0=$ non-elective. The outcome variable, mortality, was defined as death within 30 days post-surgery and the outcome variable, morbidity, was defined as any ACP-defined complication. The overall performance of the model was assessed using techniques designed to test both calibration and discrimination. The HosmerLemeshow ${ }^{8-11}$ methodology was followed to assess the calibration of the model. Calibration refers to the agreement between predicted probabilities and true probabilities (goodness-of-fit). Naturally, the true probability of a patient's outcome is not known; otherwise there would be no use to developing these prognostic models. However, true probabilities can be approximated by taking the mean of the observed outcomes within predefined groups of patients. This involves the use of the chisquared test to compare frequency tables obtained from prospective application of the equations. This is a null hypothesis test. A p-value $<0.05$ indicates a significant lack of fit. While it is possible to say that a model is wrong i.e. did not predict outcome, it is not possible to state that a particular model is correct, only that it performed adequately.

Discrimination refers to a model's ability to distinguish survivors from non-survivors. The discriminative ability of the model was assessed using the c-index (equivalent to the area under the receiver-operator characteristic (ROC) curve. Discrimination is the ability of the model to appropriately rank patients in terms of risk - that is, the

model's ability to ascribe high risks to high-risk patients and vice-versa. Values of 0.5 
indicate that the model does not predict better than chance. It is generally accepted that reasonable models produce values in the range of 0.7 to 0.8 and good models give values 0.8 to 0.9 . Forward stepwise regression was performed by adding each variable in turn (age, gender, mode-of-admission, sodium, potassium, urea, creatinine, white cell count, haemoglobin and albumin) and excluding variables with a $p$-value $>0.10$. The models were derived using the statistical programming language $\mathrm{R}$ version 2.5.1 (The R Foundation for Statistical Computing, Vienna, Austria) using the Design package (version 2.1-1). 


\section{Results}

The basic characteristics of the study population are summarised in tables $2-4$. The data used contained 704 complete records. Binary logistic regression analysis of the laboratory and administrative data of the training set produced the outcome models for colorectal resection for cancer.

\section{Mortality models}

It was found that the mortality model could successfully predict colorectal cancer mortality (Table 5). The outcome of the logistic regression model for prediction of mortality, i.e. death within 30 days, was as follows (based on $n=704$ cases):

$$
\begin{aligned}
\ln _{e}\{R /(1-R)\} & =6.63+(-1.3458 \times \text { mode of admission }) \\
& +(0.0285 \times \text { age on admission })+(0.1057 \times \text { urea }\{\mathrm{mmol} / /\}) \\
& +(-0.0646 \times \text { sodium }\{\mathrm{mmol} / /\})+(-0.0613 \times(\text { albumin })\{\mu \mathrm{mol} / /\}))
\end{aligned}
$$

A total of 50 patients within the dataset died within 30 days of surgery. The model suggested good discrimination: $\mathrm{c}$-index $=0.811$.

\section{Morbidity models}

The outcome of the logistic regression model for the prediction of morbidity was as follows (based on $n=704$ cases):

$$
\begin{aligned}
\ln _{e}\{R /(1-R)\} & =6.51+(-1.0131 \times \text { mode of admission }) \\
& +(0.0080 \times \text { age on admission })+(0.0841 \times \text { urea }\{\mathrm{mmol} / /\}) \\
& +(-0.0538 \times \text { sodium }\{\mathrm{mmol} / /\})+(-0.0410 \times(\text { albumin })\{\mu \mathrm{mol} / /\}))
\end{aligned}
$$

A total of 80 patients within the dataset had a complication post surgery. The models discrimination (c-index) was 0.697 (table 6). 


\section{Discussion}

A scoring system capable of reliable, reproducible predictions of post-operative outcomes from minimal data would be a useful tool in surgical practice. It would allow clinicians the opportunity of tailoring informed consent to individuals and aid the prioritisation of critical-care resource allocation. Colorectal cancer is a common condition and when dealing with large volumes of patients, data collection can become a burden to busy clinicians. We have derived a 'data economic' model to predict post operative morbidity and mortality in patients undergoing colorectal cancer resection. The $\mathrm{CR}-\mathrm{BHOM}$ is derived from variables obtained during routine preoperative work-up with no additional data collection requirements. This has distinct advantages over the existing scoring systems that are already established within surgical practice.

For instance, POSSUM and P-POSSUM are scoring systems that have been extensively validated across different geographical locations but are recognised to have limitations in application to patients undergoing colorectal surgery ${ }^{12-16}$. The concern that POSSUM and P-POSSUM over-predicted mortality in colorectal surgical patients led to the development of a specialty-specific POSSUM score called colorectal-POSSUM ${ }^{13}$. This used fewer physiological variables in its calculation, only 6 instead of 12, and 4 operative measurements. In comparison, CRPOSSUM was found to be a more accurate predictor of post-operative mortality in patients undergoing colorectal resection ${ }^{17}$. Despite the reduced data requirements for CR-POSSUM, there remains an issue regarding the subjective nature of the variables used. For example, the degree of peritoneal soiling (major / minor) may be perceived differently by different observers. 
The Association of Coloproctology of Great Britain and Ireland (ACPGBI) model ${ }^{18}$ is open to the same criticism. This scoring system assesses five operative variables; age, grade, Dukes stage and operative urgency and relies heavily on the fifth, the American Society of Anesthesiologists (ASA) grade, which is also subjective in nature.

$\mathrm{CR}-\mathrm{BHOM}$, in comparison, is derived from data that is entirely objective, measured independently in laboratories adhering to a nationally agreed standard. It differs from earlier models, vascular- $\mathrm{BHOM}^{3}$ and amputation-BHOM, ${ }^{6}$ with the inclusion of albumin as a predictor. Serum albumin concentration is a more sensitive indicator of surgical outcome than many other pre-operative patient characteristics ${ }^{19}$. Hypoalbuminaemia has long been recognised to reflect malnutrition and disease, and more recently to be an independent risk factor for developing post-operative complications following rectal cancer surgery ${ }^{20}$. It is thought that 'cancer cachexia' results in altered metabolism and impairment of hepatic protein synthesis, a process mediated by tumour necrosis factor alpha ${ }^{21}$. Low protein levels and thus reduced collagen synthesis at the site of surgical wounds and at bowel anastomoses could account for the higher rate of wound infections and anastomotic leakage seen. Serum albumin levels are also affected by trauma and surgical stress. Consequently, scoring systems that quantify pre-operative risk and surgical stress may be more useful than albumin levels alone. The Estimation of Physiological Ability and Surgical Stress (E-PASS) score ${ }^{22}$ reflects how the interaction between the patient's physiological reserve and surgical stress inflicted at operation can impact upon the likelihood of post-operative complications. CR-BHOM does not take into account operative variables and thus factors such as faecal contamination and excessive intra-operative blood loss which will impact on post-operative outcome are not 
considered $^{23}$. These factors could be considered iatrogenic and therefore should be excluded from a pre-operative risk model.

Post operative morbidity was not predicted as accurately as post-operative mortality by CR-BHOM. One of the reasons for this may lie in the variability and subjective nature of reporting postoperative complications. Other limitations of our model are not specific to CR-BHOM. Geographical variation resulting in diversity of case mix between different centres will impact upon the reproducibility of model outcomes. CR-BHOM needs to be validated and probably refined in many centres at different geographical locations and compared against existing scoring systems (CRPOSSUM). As the principles of clinical governance and revalidation become more important, simple scoring systems become more attractive. If reproducibility can be proven across a range of centres, CR-BHOM will provide a truly objective tool for comparative audit. Extrapolation to other conditions may then also be considered.

\section{Conclusions}

CR-BHOM shows good discrimination for the prediction of post-operative mortality following colorectal surgery. With the inclusion of pre-operative albumin levels in the equation, CR-BHOM can provide more accurate and more useful information with regards to post-operative outcomes. The main advantage of being a data economic model eases its utilisation by surgeons in the pre-operative decision making process. 
Acknowledgements: We wish to acknowledge Mr NJ Keeling, Mr JC Albert, Sr M Harold and Alison Schofield for their contribution. The co-authors from the University of Cambridge, Department of Radiology, wish to acknowledge a National Institute of Health Research, Biomedical Research Centre grant. 


\section{References:}

1. Copeland GP, Jones D, Walters M. POSSUM: a scoring system for surgical audit. Br J Surg 1991;78(3): 355-360.

2. $\quad$ Prytherch DR, Whiteley MS, Higgins B, Weaver PC, Prout WG, Powell SJ. POSSUM and Portsmouth POSSUM for predicting mortality. Physiological and Operative Severity Score for the enUmeration of Mortality and morbidity. Br J Surg 1998;85(9): 1217-1220.

3. Tang T, Walsh SR, Prytherch DR, Lees T, Varty K, Boyle JR. VBHOM, a data economic model for predicting the outcome after open abdominal aortic aneurysm surgery. Br J Surg 2007;94(6): 717-721.

4. $\quad$ Prytherch DR, Sirl JS, Weaver PC, Schmidt P, Higgins B, Sutton GL. Towards a national clinical minimum data set for general surgery. Br J Surg 2003;90(10): 1300-1305.

5. Prytherch DR, Ridler BM, Ashley S. Risk-adjusted predictive models of mortality after index arterial operations using a minimal data set. Br J Surg 2005;92(6): 714-718.

6. Tang TY, Prytherch DR, Walsh SR, Athanassoglou V, Seppi V, Sadat U, Lees TA, Varty K, Boyle JR. The development of a VBHOM-based outcome model for lower limb amputation performed for critical ischaemia. Eur $J$ Vasc Endovasc Surg 2009;37(1): 62-66.

7. Harrell FE, Jr., Lee KL, Califf RM, Pryor DB, Rosati RA. Regression modelling strategies for improved prognostic prediction. Stat Med 1984;3(2): 143-152.

8. Hosmer DJ, Lemeshow, S. Goodness of fit tests for the multiple logistic regression model. Commun Stat Theor Meth 1980;A9: 1043-1069.

9. Hosmer DJ, Lemeshow, S, Klar, J. Goodness-of-fit testing for multiple logistic regression analysis when the estimated probabilities are small

Biometrical Journal 1988;30: 911-924.

10. Hosmer DJ, Lemeshow S. Applied Logistic Regression. New York: Wiley 1989.

11. Lemeshow S, Hosmer, DW Jr. A review of goodness of fit statistics for use in the development of logistic regression models Am J Epidemiol 1982;115: 92-106.

12. Menon KV, Farouk R. An analysis of the accuracy of P-POSSUM scoring for mortality risk assessment after surgery for colorectal cancer. Colorectal Dis 2002;4(3): 197-200.

13. Tekkis PP, Prytherch DR, Kocher HM, Senapati A, Poloniecki JD, Stamatakis JD, Windsor AC. Development of a dedicated risk-adjustment scoring system for colorectal surgery (colorectal POSSUM). Br J Surg 2004;91(9): 1174-1182.

14. Ferjani AM, Griffin D, Stallard N, Wong LS. A newly devised scoring system for prediction of mortality in patients with colorectal cancer: a prospective study. The lancet oncology 2007;8(4): 317-322.

15. Vather R, Zargar-Shoshtari K, Adegbola S, Hill AG. Comparison of the possum, P-POSSUM and Cr-POSSUM scoring systems as predictors of postoperative mortality in patients undergoing major colorectal surgery. ANZ journal of surgery 2006;76(9): 812-816.

16. Ugolini G, Rosati G, Montroni I, Zanotti S, Manaresi A, Giampaolo L, Taffurelli $\mathrm{M}$, Pricolo $\mathrm{V}$. An easy-to-use solution for clinical audit in colorectal cancer surgery. Surgery 2009;145(1): 86-92. 
17. Bromage SJ, Cunliffe WJ. Validation of the CR-POSSUM risk-adjusted scoring system for major colorectal cancer surgery in a single center. Diseases of the colon and rectum 2007;50(2): 192-196.

18. Tekkis PP, Poloniecki JD, Thompson MR, Stamatakis JD. Operative mortality in colorectal cancer: prospective national study. BMJ (Clinical research ed 2003;327(7425): 1196-1201.

19. Gibbs J, Cull W, Henderson W, Daley J, Hur K, Khuri SF. Preoperative serum albumin level as a predictor of operative mortality and morbidity: results from the National VA Surgical Risk Study. Arch Surg 1999;134(1): 36-42.

20. Lohsiriwat V, Lohsiriwat D, Boonnuch W, Chinswangwatanakul V, Akaraviputh $\mathrm{T}$, Lert-Akayamanee N. Pre-operative hypoalbuminemia is a major risk factor for postoperative complications following rectal cancer surgery. World J Gastroenterol 2008;14(8): 1248-1251.

21. Scarfone A, Capristo E, Valentini G, Addolorato G, Ghittoni G, Giancaterini A, Mingrone G, Greco AV, Gasbarrini G. Wasting in gastrointestinal tract cancers:

clinical and etiologic aspects. Minerva gastroenterologica e dietologica 1999;45(4): 261-270.

22. Tang T, Walsh SR, Fanshawe TR, Gillard JH, Sadat U, Varty K, Gaunt ME, Boyle JR. Estimation of physiologic ability and surgical stress (E-PASS) as a predictor of immediate outcome after elective abdominal aortic aneurysm surgery. American journal of surgery 2007;194(2): 176-182.

23. Metcalfe MS, Norwood MG, Miller AS, Hemingway D. Unreasonable expectations in emergency colorectal cancer surgery. Colorectal Dis 2005;7(3): 275278. 
Table 1: Definition of major complications

\begin{tabular}{ll}
\hline & Major \\
\hline Leak & $\begin{array}{l}\text { Clinical evidence of anastomotic breakdown with or } \\
\text { without radiological confirmation }\end{array}$ \\
Abscess & Wound, intra abdominal or pelvic pus \\
Post-op bleeding & Gastrointestinal, intra abdominal or wound bleeding \\
Bowel obstruction & Postoperative bowel obstruction \\
\hline $\begin{array}{l}\text { Major complication: a complication that required re-operation, interventional } \\
\text { radiology, ITU/HDU care or delays discharge by }>72 \text { hours }\end{array}$
\end{tabular}

Table 2: Patient Demographics

\begin{tabular}{lcc}
\hline Variable & Number & $\begin{array}{c}\text { Included in } \\
\text { model }\end{array}$ \\
\hline Median age (years) & $74,($ range $28-98)$ & $\mathrm{Y}$ \\
Male & $55.4 \%$ & $\mathrm{Y}$ \\
Mean Haemoglobin $(\mathrm{g} / \mathrm{dl})$ & $12.5( \pm 2.1)$ & $\mathrm{Y}$ \\
Mean White Cell Count $\left(10^{9} / \mathrm{l}\right)$ & $8.9( \pm 3.3)$ & $\mathrm{Y}$ \\
Mean serum Sodium $(\mathrm{mmol} / \mathrm{l})$ & $138.1( \pm 3.9)$ & $\mathrm{Y}$ \\
Mean serum Potassium $(\mathrm{mmol} / \mathrm{l})$ & $4.3( \pm 0.5)$ & $\mathrm{Y}$ \\
Mean serum Urea $(\mathrm{mmol} / \mathrm{l})$ & $6.2( \pm 3)$ & $\mathrm{Y}$ \\
Mean serum Albumin $(\mu \mathrm{mol} / \mathrm{l})$ & $39.6( \pm 6.3)$ & $\mathrm{Y}$ \\
Mean serum Creatinine $(\mu \mathrm{mol} / \mathrm{l})$ & $89.2( \pm 28.6)$ & $\mathrm{Y}$ \\
Emergency admission & $18.6 \%$ & $\mathrm{Y}$ \\
Median ASA Score $(\mathrm{range})$ & $2(1-4)$ & $\mathrm{N}$ \\
Observed in hospital mortality & $7.1 \%$ & $\mathrm{~N}$ \\
Observed in hospital morbidity & $11.4 \%$ & $\mathrm{~N}$ \\
\hline
\end{tabular}

Total $(n=704)$, normally distributed values quoted as mean ( \pm stdev) 


\begin{tabular}{ll}
\hline Operation site & No. of Patients \\
\hline Right colon & 280 \\
Left colon & 173 \\
Rectum & 251 \\
\hline
\end{tabular}

Table 4: Length of Stay

\begin{tabular}{cc}
\hline $\begin{array}{c}\text { Hospital stay } \\
\text { (days) }\end{array}$ & $\begin{array}{c}\text { Number of } \\
\text { patients }\end{array}$ \\
\hline $0-5$ & 16 \\
6 to 10 & 259 \\
11 to 20 & 286 \\
21 to 30 & 56 \\
$>30$ & 43
\end{tabular}

Seven patients died within 30 days of surgery but after discharge from hospital.

Table 5: Mortality - Prospective application of the new CR-BHOM Model

\begin{tabular}{lccccc}
\hline $\begin{array}{c}\text { Predicted } \\
\text { Mortality (\%) }\end{array}$ & $\begin{array}{c}\text { No. of } \\
\text { Patients }\end{array}$ & $\begin{array}{c}\text { Mean } \\
\text { Predicted } \\
\text { Risk (\%) }\end{array}$ & $\begin{array}{c}\text { Predicted } \\
\text { Deaths }\end{array}$ & $\begin{array}{c}\text { Reported } \\
\text { Deaths }\end{array}$ & $\mathrm{X}^{2}$ \\
\hline$>0$ to $<7$ & 525 & 3.01 & 16 & 19 & 0.658 \\
$>7$ to $<12$ & 68 & 9.01 & 6 & 5 & 0.228 \\
$>12$ to $<33$ & 86 & 19.05 & 16 & 14 & 0.429 \\
$>33$ to $<100$ & 25 & 46.74 & 12 & 12 & 0.016 \\
$>0$ to $<100$ & 704 & 7.79 & 50 & 50 & 1.331 \\
\hline BHOM model, $X^{2}=1.331$, d.f. $=4$, p-value $=0.856 ;$ no evidence of lack of fit, c-index $=$ \\
0.81
\end{tabular}

Table 6: Morbidity - Prospective application of the new CR-BHOM Model 


\begin{tabular}{cccccc}
\hline $\begin{array}{c}\text { Predicted } \\
\text { Morbidity } \\
\text { (\%) }\end{array}$ & $\begin{array}{c}\text { No. of } \\
\text { Patients }\end{array}$ & $\begin{array}{c}\text { Mean } \\
\text { Predicted } \\
\text { Risk (\%) }\end{array}$ & $\begin{array}{c}\text { Predicted } \\
\text { Events }\end{array}$ & $\begin{array}{c}\text { Reported } \\
\text { Events }\end{array}$ & $\mathrm{X}^{2}$ \\
\hline$>0$ to $<7$ & 298 & 5.43 & 16 & 17 & 0.045 \\
$>7$ to $<12$ & 221 & 8.91 & 20 & 23 & 0.608 \\
$>12$ to $<33$ & 155 & 19.56 & 30 & 23 & 2.193 \\
$>33$ to $<100$ & 30 & 46.08 & 14 & 17 & 1.352 \\
$>0$ to $<100$ & 704 & 12.02 & 80 & 80 & 4.198 \\
\hline
\end{tabular}

BHOM model, $x^{2}=4.198$, d.f. $=4, p$-value $=0.380$; no evidence of lack of fit, $c$-index $=$ 0.697 